\title{
Characteristics of VHF radiowave scintillations over a solar cycle $(1983-1993)$ at a low-latitude station: Waltair $\left(17.7^{\circ} \mathrm{N}, 83.3^{\circ} \mathrm{E}\right)$
}

\author{
P. V. S. Rama Rao, P. T. Jayachandran, P. Sri Ram, \\ B. V. Ramana Rao, D. S. V. V. D. Prasad, K. K. Bose \\ Space Physics Laboratory, Department of Physics, Andhra University, Visakhapatnam-530 003, India
}

Received: 10 January 1996 / Revised: 16 December 1996 / Accepted: 13 February 1997

\begin{abstract}
The characteristics of VHF radiowave scintillations at $244 \mathrm{MHz}$ (FLEETSAT) during a complete solar cycle (1983-93) at a low-latitude station, Waltair $\left(17.7^{\circ} \mathrm{N}, 83.3^{\circ} \mathrm{E}\right)$, are presented. The occurrence of night-time scintillations shows equinoctial maxima and summer minima in all the epochs of solar activity, and follows the solar activity. The daytime scintillation occurrence is negatively correlated with the solar activity and shows maximum occurrence during the summer months in a period of low solar activity. The occurrence of night-time scintillations is inhibited during disturbed days of high solar activity and enhanced during low solar activity.
\end{abstract}

\section{Introduction}

Man's interest in the ionosphere developed largely because of ionospheric communications, the improvement of which depends upon increased knowledge on short- and long-term behaviour of the ionosphere. The study of radiowave scintillation is important in understanding the basic mechanism of generation of ionospheric irregularities as well as planning satellite-based communication systems and developing satellite-based radar systems. The ionosphere results from the process of ion production, balanced by loss and transport. The balance is achieved by complex intermediate steps. The complex processes vary markedly through a solar cycle. Studies of solar-cycle variation of ionospheric irregularities that produce scintillations help a long way in planning transionospheric communication systems.

In the Indian zone, detailed studies of equatorial scintillation began with the multifrequency observations during the period when the ATS-6 satellite (1975-76) was positioned at a longitude of $34^{\circ} \mathrm{E}$. The basic features of the scintillations at Ootacamund $\left(\operatorname{dip} 6^{\circ} \mathrm{N}\right)$ have been

Correspondence to: P. V. S. Rama Rao reported by Rastogi et al. (1982), which showed an equinoctial maxima.

The occurrence of equatorial scintillations has revealed a puzzling pattern that appears to vary both with season and longitude (Aarons, 1977; Basu and Basu, 1981). Scintillation activity has been found to maximise at some observing stations around equinox (Koster, 1972; Krishna Murthy et al., 1978; Mathew et al., 1991; Pathan et al., 1991) and other stations around solstice (e.g. Aarons et al., 1980; Livingston et al., 1980). Besides the difference in the seasonal behaviour among the observing stations, satellite and multistation observations have revealed distinct longitudinal variations in the occurrence during a given season (Sharma and Meldrew, 1975; Aarons et al, 1980).

This paper presents, for the first time in the Indian sector, the continuous and long-term behaviour of the VHF radiowave scintillations at a low-latitude station over a complete solar cycle period (1983-1993).

\section{Data}

The amplitude variations of the $244-\mathrm{MHz}$ beacon signals from the geostationary satellite, FLEETSAT $\left(75^{\circ} \mathrm{E}\right)$, are recorded at a low-latitude station, Waltair $\left(17.7^{\circ} \mathrm{N}, 83.3^{\circ} \mathrm{E}\right)$, from September 1983 to September 1993. The data are analysed to study the percentage occurrence of scintillations. The amplitude variations greater than the $6-\mathrm{dB}$ level are scaled for every $15 \mathrm{~min}$ and are used for the present study.

The data have been grouped into three seasons as follows. (1) Equinox: March, April, September and October, (2) Winter: November, December, January and February. (3) Summer: May, June, July and August.

\section{Results}

\subsection{Seasonal variation of night-time scintillations}

The seasonal variation of scintillation occurrence for the three different seasons, namely equinox, winter and 
summer for the periods 1988-89 (representing high solar activity, $R z=131.9$ and $F 10.7=177.1)$ and $1984-86$ (representing low solar activity, $R z=33$ and $F 10.7=$ 89) are presented in Fig. 1. It is seen from the figure that the occurrence is maximum during the equinox, followed by winter and minimum in summer, irrespective of solar activity. The seasonal occurrence pattern is the same also for the other years and shows the repeatability of the occurrence pattern.

\subsection{Solar-cycle variation of night-time scintillations}

The monthly average variation in the occurrence of scintillations along with the corresponding monthly average sunspot number $(R z)$ and solar flux index $(F 10.7)$ are presented in Fig. 2. The top panel in the figure represents the scintillation occurrence and the bottom panel the variation of $R z$ (dotted line) and $F 10.7$ (solid line). The best fit of this variation is also shown in the figure (2a). The correlation coefficients between the occurrence of scintillation, sunspot number and $F 10.7$ are shown in Table 1. The occurrence of scintillation is well correlated with the sunspot number and $F 10.7$ during the equinoctial months $(r=0.81)$ followed by winter $(r=0.61)$ and summer months $(r=0.63)$.

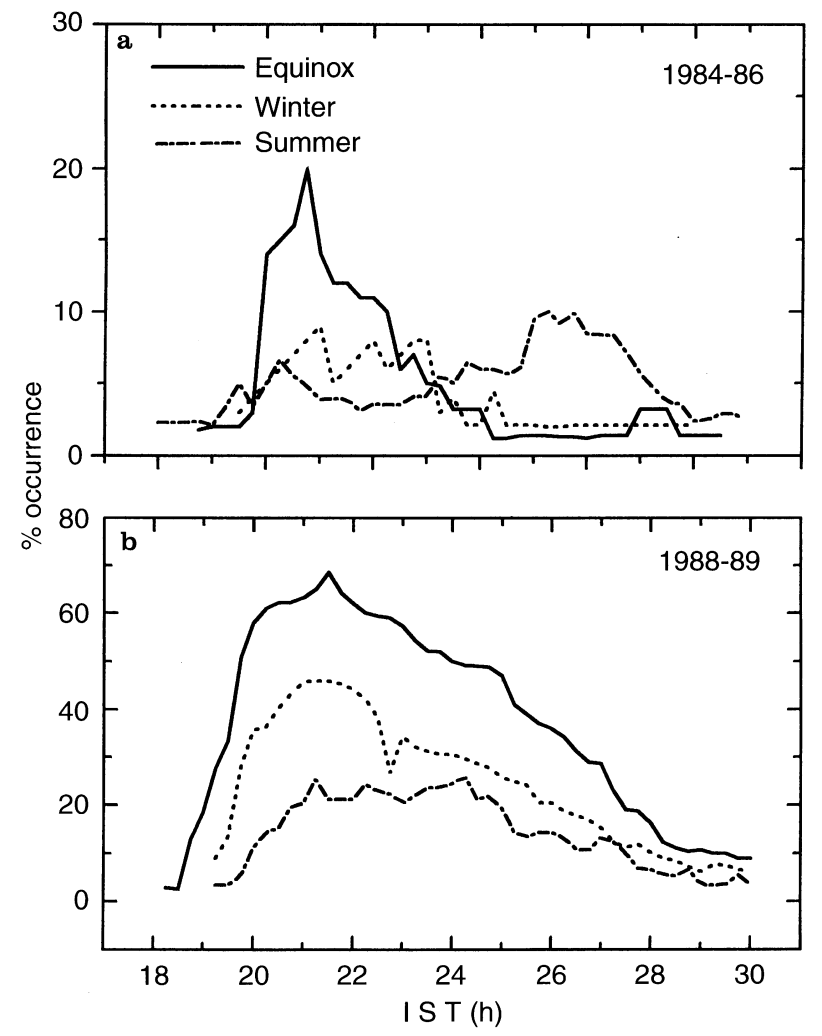

Fig. 1a, b. Average seasonal variation of percentage occurrence of scintillations during a 1984-1986 (low solar-activity period) and b 1988-1989 (high solar-activity period)
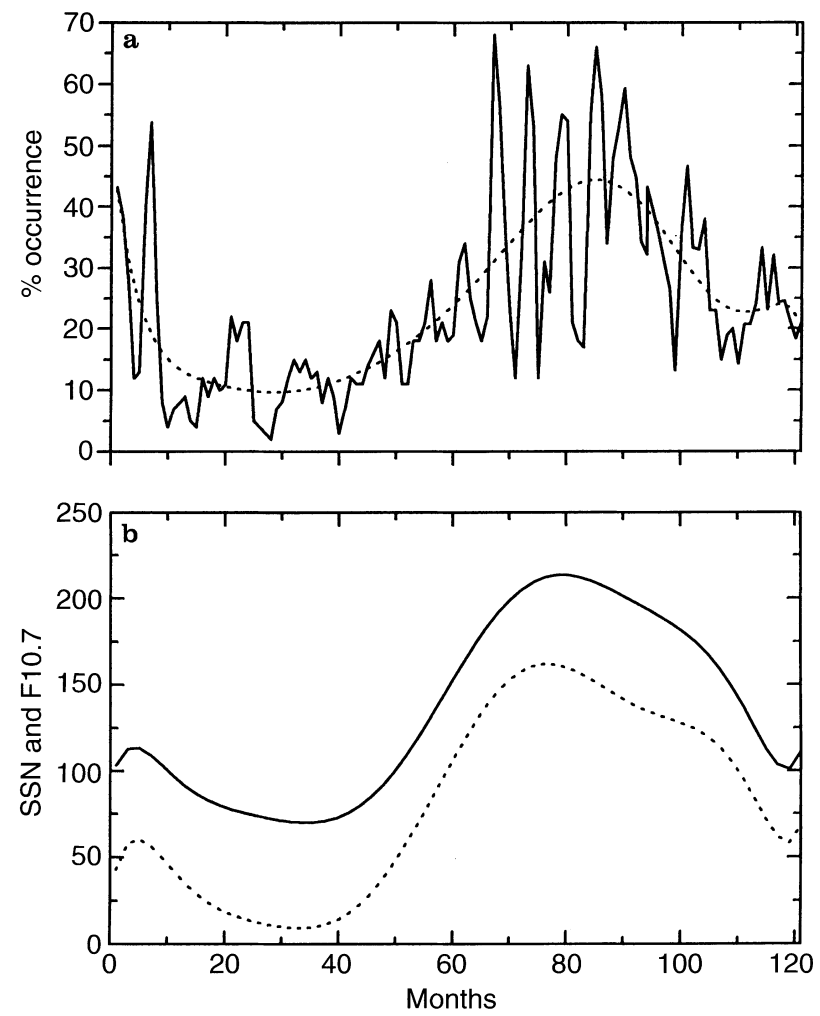

Fig. 2a, b. Variation of monthly mean a percentage occurrence of night-time scintillations and $\mathbf{b} R z$ (dashed curve) and $F 10.7$ (solid line) for the period 1983-1993

\subsection{Daytime scintillations}

Although the occurrence of scintillations over this station (low latitude) is mostly confined to the local night-time during high and low solar-activity periods, the occurrence of daytime scintillation is also a typical feature during low solar-activity periods, especially during summer months. An attempt is made to study the occurrence of daytime scintillations over a complete solar cycle.

The monthly mean variation of the occurrence of daytime scintillations is shown in Fig. 3. The occurrence of daytime scintillation is maximum $(15 \%)$ during the summer months of low solar activity (1985-1986) and minimum $(2 \%)$ during the equinoctial months of high

Table 1. The correlation coefficients of occurrence of night-time scintillations with sunspot number and $F 10.7$ for the three seasons and the total period of observation

\begin{tabular}{lll}
\hline Season & \multicolumn{2}{l}{ Correlation coefficient $(r)$} \\
\cline { 2 - 3 } & sunspot number & $F 10.7$ \\
\hline Equinox & 0.81 & 0.84 \\
Winter & 0.61 & 0.61 \\
Summer & 0.63 & 0.66 \\
Total period & 0.82 & 0.85 \\
\hline
\end{tabular}




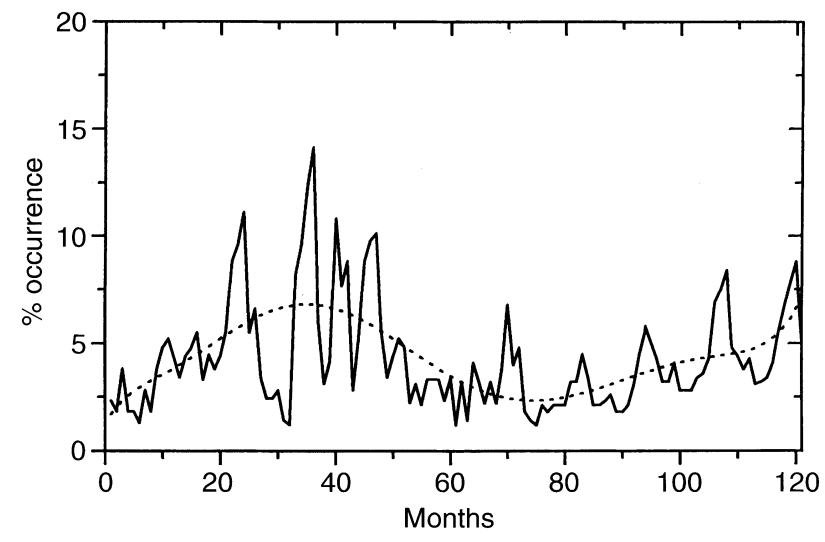

Fig. 3. Variation of monthly mean percentage occurrence of daytime scintillations for the period 1983-1993

Table 2. The correlation coefficients of occurrence of daytime scintillations with sunspot number and $F 10.7$ for the three seasons and the total period of observation

\begin{tabular}{lll}
\hline \multirow{2}{*}{ Season } & \multicolumn{2}{l}{ Correlation coefficient $(r)$} \\
\cline { 2 - 3 } & sunspot number & $F 10.7$ \\
\hline Equinox & -0.45 & -0.31 \\
Winter & -0.50 & -0.48 \\
Summer & -0.64 & -0.64 \\
Total period & -0.43 & -0.43 \\
\hline
\end{tabular}

solar activity (1989-1990). This figure, when compared with Fig. 2, shows that the occurrence of daytime scintillations varies inversely with the solar activity. The correlation coefficients of the scintillation activity with $F 10.7$ and $R z$ are given in Table 2. The negative correlation is maximum $(-0.64)$ during summer months and minimum $(-0.31)$ during equinoctial months.

\subsection{Effect of magnetic activity on the occurrence of night-time scintillations}

Two different periods each in low and high solar activity are considered, to study the magnetic activity effect on the occurrence of night-time scintillation. The periods 1990-1992 $(R z=153, F 10.7=208)$ and 1986-1989 $(R z=141, F 10.7=198)$ represent the high solar-activity periods and $1992-1993(R z=38, F 10.7=87), 1984$ $1986(R z=31, F 10.7=91)$ represent the low solaractivity periods. The variations of scintillation activity during these periods are shown in Fig. 4. The solid line represents the occurrence of scintillations during quiet days $(A p<10)$ and dotted line represents the occurrence of scintillations during disturbed days $(A p>10)$. It is seen from the figure that scintillation occurrence is higher on quiet days than on disturbed days during high solar-activity periods (a \& b) and disturbed-day scintillations are higher than those of quiet days during the periods of low solar activity (c \& d).
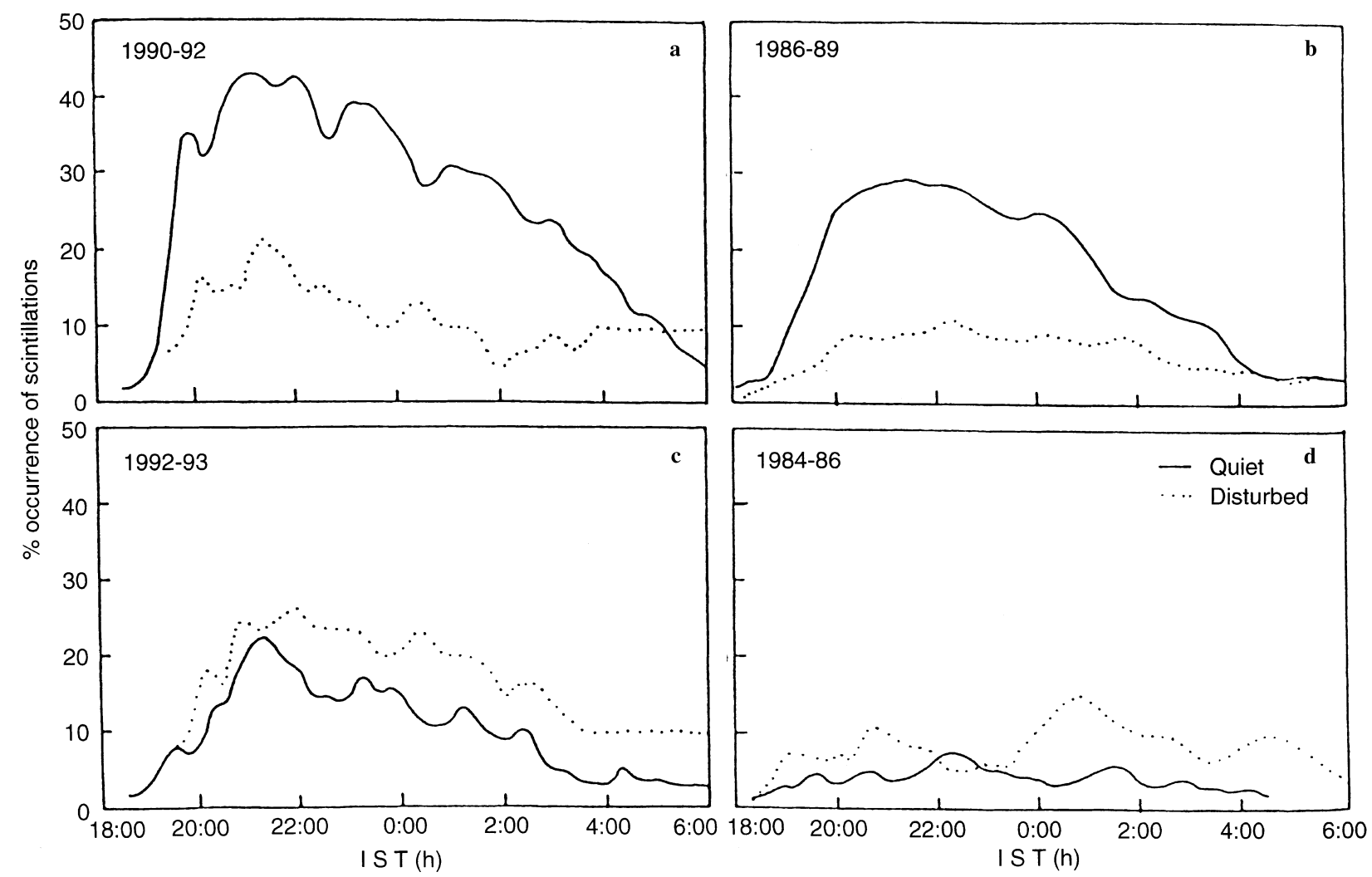

Fig. 4a-d. Nocturnal variation of average percentage occurrence of scintillations for magnetically quiet and disturbed days of a 1990-1992, b 1986-1989, c 1992-1993 and d 1984-1986 


\section{Discussion and conclusions}

The occurrence of scintillations shows seasonal, latitudinal and longitudinal variability (e.g. Aarons, 1993). The longitudinal variability in the occurrence of scintillations is due to the longitudinal variation of the geomagnetic field (Burke et al., 1980; Maruyama and Matuura, 1980; Abdu et al., 1981). Seasonal dependence is questionable because the mechanisms believed to be responsible for the F-region irregularities producing equatorial scintillations involve entire geomagnetic flux tubes which extend to conjugate hemispheres (Tsunoda, 1980; Weber et al., 1983). Aarons et al. (1980, 1981) attempted to resolve the contradiction by hypothesising that asymmetric hemispherical variation in F-region plasma-density distribution (associated with the equatorial anomaly) might be responsible for the apparent local seasonal dependence, which was later confirmed by Jayachandran et al. (1997).

The solar-activity dependence of the scintillation occurrence was reported earlier by many workers. Rastogi (1982) found very little association of solar activity on the scintillation occurrence in the American sector. Rastogi et al. (1977), Mathew et al. (1991) and Pathan et al. (1991) have reported the dependence of equatorial scintillation occurrence on sunspot numbers in the Indian sectors. Dasgupta et al. (1981) have shown that the occurrence of scintillations at Calcutta $\left(16.8^{\circ} \mathrm{N}\right.$ dip lat.) depends highly on solar activity during equinoctial and winter months, but not so during summer months. They suggested that the scintillation occurrence during winter and equinoctial months are of equatorial origin and during summer months are of local origin. The data of the preceding studies are limited to a maximum of 5 years. In the present study, the correlation of scintillation occurrence with sunspot number and $F 10.7$ is presented for all the three seasons and for the complete solar cycle.

Although ionospheric radiowave scintillation is mainly a night-time phenomenon, scintillations do also occur in daytime. The daytime scintillation studies have not received much attention because of the relatively low frequency of their occurrence. The earlier studies have shown that the daytime scintillation is mainly associated with sporadic-E, except at polar and auroral regions (Wild and Roberts, 1956; Briggs, 1958). At mid-latitudes, daytime scintillation occurrence has a seasonal variation maximising during summer months (Aarons et al., 1963). Rastogi and Mullen (1981) have reported daytime scintillations at Huancayo in the summer months of minimum solar-activity periods. Hajkowicz and Dearden (1988) have studied the characteristics of radiowave scintillations over a solar cycle (1973-1985) using the $150-\mathrm{MHz}$ transmission from polar orbiting satellites at Brisbane and found a pronounced increase in daytime scintillations in southern winter throughout the solar cycle. The work of Dasgupta and Kersley (1976), Rastogi et al. (1977) and Rastogi (1980) showed a positive relationship between the sporadic-E and daytime scintillations. A careful study on the midlatitude sporadic-E by Chadwick (1962) revealed that there is a marked increase in the sporadic-E occurrence during the summer months of low solar-activity period. The lifetime of sporadic-E clouds during sunspot minima is considerably larger than that during sunspot maxima (Chavdarov et al., 1966). The sporadic-E maximises during the summer months in the period of low solar activity at Waltair (Sahu, 1986). These results agree with those of the present study on daytime scintillation occurrence at this station.

The results presented here show that (1) the nighttime scintillation occurrence follows solar activity, (2) the seasonal pattern observed in the scintillation occurrence remains the same in any given epoch of solar activity, (3) the occurrence of daytime scintillation is negatively correlated with solar activity, which shows maximum occurrence during the summer months of low solar-activity periods, and (4) the occurrence of nighttime scintillations is inhibited during the disturbed days of the high solar-activity period and is enhanced during the low solar-activity periods.

Acknowledgement. Part of this work is sponsored by Dept. of Science and Technology (Govt. of India). Two of the authors (PTJ and PS) thank CSIR (Govt. of India) for awarding research fellowships.

Topical Editor D. Alcaydé thanks S. Basu and N. Balan for their help in evaluating this paper.

\section{References}

Aarons, J., Equatorial scintillations: a review, IEEE Trans. Ant. Prop., 25, 729, 1977.

Aarons, J., The longitudinal morphology of equatorial spread-Flayer irregularities relevant to their occurrence, Space. Sci. Rev., 63, 209, 1993.

Aarons, J., J. P. Mullen, and S. Basu, Geomagnetic control of satellite scintillations, J. Geophys. Res., 68, 33159, 1963.

Aarons, J., J. P. Mullen, J. R. Koster, R. F. da Silva, J. R. Mederios, R. T. Mederios, R. Bushby, J. Pantoja, J. Lanat, and M. R. Paulson, Seasonal and geomagnetic control of equatorial scintillations in two longitude sectors, J. Atmos. Terr. Phys., 42, 681, 1980

Aarons, J., H. E. Whitney, E. Mackenzie, and S. Basu, Microwave equatorial scintillation intensity during solar maximum., Radio Sci., 16, 939, 1981.

Abdu, M. A., J. A. Bittencourt, and I. S. Batista, Magnetic declination control of the equatorial F-region dynamo electric field development and spread-F, J. Geophys. Res., 86, 11443, 1981

Basu, S., and Su Basu, Equatorial scintillations - a review, J. Atmos. Terr. Phys., 43, 473, 1981.

Briggs, B. H., The diurnal and seasonal variations of spread-F ionospheric echoes and the scintillation of radio star, J. Atmos. Terr. Phys., 12, 89, 1958.

Burke, W. J., D. E. Donatelli, and R. C. Sagalyn, The longitudinal distribution of equatorial spread-F bubbles in the topside ionosphere, J. Geophys. Res., 85, 1335, 1980.

Chadwick, W. B., The ionospheric sporadic-E, Pergamon Press, New York, 1962.

Chavdarov, S. S., S. P. Chernysheva, and Kh. Z. Shatkhin, Stability of reflections from sporadic-E-layers and solar activity, $\mathrm{Ge}$ omagn. Aeron., 6, 109, 1966.

Dasgupta, A., and L. Kersley, Summer daytime scintillations and sporadic-E, J. Atmos. Terr. Phys., 38, 615, 1976.

Dasgupta, A., A. Maitra, and S. Basu, Occurrence of nighttime VHF scintillations near the equatorial anomaly crest in the Indian sector, Radio Sci., 16, 1455, 1981. 
Hajkowicz, L. A., and D. J. Dearden, Observations of random and quasi-periodic scintillations at southern mid-latitudes over a solar cycle, J. Atmos. Terr. Phys., 50, 511, 1988.

Jayachandran, P. T., P. Sriram, V. V. Somayajulu, and P. V. S. Rama Rao, Effect of equatorial ionization anomaly on the occurrence of spread-F, Ann. Geophysicae, 1997.

Koster, J. R., Equatorial scintillations, J. Planet. Space Sci., 10, 1999, 1972.

Krishna Murthy, K., C. Raghava Reddi, and B. V. Krishna Murthy, Nighttime ionospheric scintillations at the magnetic equator, SPL VSSC Tech. Rep., 46, 1978.

Livingston, R. C., Comparison of multi-frequency equatorial scintillations: American and Pacific sectors, Radio Sci., 15, 801, 1980.

Maruyama, T., and N. Matuura, Global distribution of occurrence probability of spread-F echoes based on ISS-b observations, $J$. Radio Res. Labs. (Japan), 27, 201, 1980.

Mathew, B., B. M. Pathan, K. N. Iyer, and D. R. K. Rao, Comparative study of scintillations at the magnetic equator and at the crest regions of the anomaly in the Indian zone, Proc. Ind. Acad. Sci. (E and P), 100, 331, 1991.

Pathan, B. M., P. V. Koparkar, R. G. Rastogi, and D. R. K. Rao, Dynamics of ionospheric irregularities producing VHF radiowave scintillations at low latitudes, Ann. Geophysicae, 9, 126, 1991.

Rastogi, R. G., Daytime radiowave scintillations in the equatorial electrojet regions, Ind. J. Rad. Space. Phys., 9, 219, 1980.
Rastogi, R. G., Solar-cycle effects on radio scintillations at Huancayo, Ind. J. Rad. Space. Phys., 11, 215, 1982.

Rastogi, R. G., and J. P. Mullen, Intense daytime radiowave scintillations and sporadic-E layer near the dip equator, J. Geophys. Res., 86, 195, 1981 .

Rastogi, R. G., M. R. Deshpande, B. S. Murthy, and K. Davies, Daytime satellite radio scintillations and sporadic-E near the magnetic equator, Geophys. Res. Lett., 4, 113, 1977.

Rastogi, R. G., H. Chandra, M. R. Deshpande, Equatorial scintillations of ATS-6 radio beacons: Phase II-Ootacamund 1975-76, Ind. J. Rad. Space. Phys., 11, 89, 1982.

Sahu, S., Studies on sporadic-E layers over Waltair, Ph.D thesis, Andhra University, 1986.

Sharma, R. P., and D. B. Meldrew, Seasonal and longitudinal variations in the occurrence frequency of magnetospheric ducts, J. Geophys. Res., 80, 977, 1975.

Tsunoda, R. T., Magnetic field-aligned characteristics of plasma bubbles in the nighttime equatorial ionosphere, J. Atmos. Terr. Phys., 42, 743, 1980.

Weber, E. S., J. Aarons, and A. L. Johnson, Conjugate studies of an isolated equatorial irregularity region, J. Geophys. Res., 88, $3175,1983$.

Wild, J. P., and J. A. Roberts, The spectrum of radio star scintillations and the nature of irregularities in the ionosphere, J. Atmos. Terr. Phys., 8, 55, 1956. 